\title{
Avaliação genética das vacinas contra a brucelose bovina comercializadas no Brasil $^{1}$
}

\author{
Renata Bastos ${ }^{2}$, Cleber O. Soares ${ }^{3}$ Carina Elisei $^{4}$, Anna L.R. Munhoz ${ }^{2}$, Nádia L. Bezerra², \\ Marrielen A.B. Caitano ${ }^{2}$ e Grácia M.S. Rosinha ${ }^{3^{*}}$
}

\begin{abstract}
Bastos R., Soares C.O., Elisei C., Munhoz A.L.R., Bezerra N.L., Caitano M.A.B. \& Rosinha, G.M.S. 2012. [Genetic evaluation of vaccine against bovine brucellosis marketed in Brazil.] Avaliação genética das vacinas contra a brucelose bovina comercializadas no Brasil. Pesquisa Veterinária Brasileira 32(10):957-962. Faculdade de Medicina Veterinária e Zootecnia, Universidade Federal de Mato Grosso do Sul, Av. Felinto Müller 2443, Ipiranga, Campo Grande, 79070-900, MS, Brazil. E-mail: rosinha@cnpgc.embrapa.br

Vaccine strains B19 and RB51 are administered to cattle for prevention against infection by Brucella abortus. However, there are reports that these vaccines can cause miscarriages. Thus, every miscarriage among vaccinated animals should be thoroughly studied to determine the cause. In Brazil, there are no records on the origin of B19 and RB51 samples used in the preparation of commercial vaccines. Therefore, a study is needed to determine possible mutations in relation to the USDA reference samples of $B$. abortus due to the fact that vaccine samples could revert to the virulence of the disease. The aim of the present study was to perform a genotype analysis of vaccine strains B19 and RB51 used in Brazil. The methodology was based on the genotyping of marker genes of these vaccine strains by amplification using polymerase chain reaction. The results allowed the identification of the genotype of the B19 and RB51 commercial vaccine available for use on cattle in Brazil. The absence of mutations in the samples tested confirmed the genetic quality of the vaccines and stability of genes analyzed.
\end{abstract}

INDEXING TERMS: Brucella abortus, brucellosis, vaccine, B19, RB51, genotyping, genetic quality.

RESUMO.- A prevenção contra infecções causadas por Brucella abortus em bovinos é realizada por meio da administração das amostras vacinais B19 e RB51. Existem relatos de que estas vacinas podem causar aborto em fêmeas vacinadas. Portanto, toda a ocorrência de aborto em animais vacinados merece um estudo aprofundado sobre a causa. No Brasil, não há registro sobre a origem das amostras B19 e RB51 utilizadas na produção das vacinas comerciais. Assim, um estudo para verificar possíveis mutações em relação às amostras referência USDA B19 e USDA RB51 de B. abortus se faz necessário, devido às amostras vacinais poderem

\footnotetext{
${ }^{1}$ Recebido em 2 de janeiro de 2012.

Aceito para publicação em 4 de abril de 2012.

${ }^{2}$ Mestranda em Ciência Animal, Programa de Pós-Graduação, Faculdade de Medicina Veterinária e Zootecnia, Universidade Federal de Mato Grosso do Sul (UFMS), Av. Felino Müller 2443, Ipiranga, Campo Grande, MS 79070-900, Brasil.

${ }^{3}$ Embrapa Gado de Corte, Av. Rádio Maia 830, Vila Popular, Campo Grande, MS 79106-550. *Autor para correspondência: rosinha@cnpgc.embrapa.br

${ }^{4}$ Programa de Pós-Graduação em Biotecnologia, Universidade Católica Dom Bosco (UCDB), Av. Tamandaré 6000, Jardim Seminário, Campo Grande, MS 79117-900
}

reverter a sua virulência. Objetivou-se com este estudo caracterizar genotipicamente as amostras vacinais B19 e RB51 comercializadas no Brasil. A metodologia utilizada foi a genotipagem de genes marcadores destas amostras vacinais, por meio da amplificação pela reação em cadeia da polimerase. Os resultados obtidos permitiram a identificação do genótipo das vacinas comerciais B19 e RB51 disponíveis e utilizadas em bovinos no Brasil. A ausência de mutações nas vacinas testadas corrobora com a qualidade genética das mesmas, quanto à estabilidade dos genes analisados.

TERMOS DE INDEXAÇÃO: Brucella abortus, brucelose, vacina, B19, RB51, genotipagem, qualidade genética.

\section{INTRODUÇÃO}

O controle de doenças infecciosas de animais no Brasil requer melhorias para atingir os padrões internacionais e aumentar a produção animal. Algumas dessas doenças, além de colocar em risco a saúde do rebanho, podem representar um problema de saúde pública, como é o caso da brucelose, causada por bactérias intracelulares facultativas do gênero Brucella. 
Uma das principais zoonoses mundiais, a brucelose, pode acometer tanto os animais silvestres quanto os animais domésticos de alto valor zootécnico. 0 gênero $\mathrm{Bru}$ cella contém diversas espécies que são definidas principalmente com base na especificidade ao hospedeiro, sendo que a maioria pode infectar seres humanos e a patologia difere de acordo com a gravidade da infecção (Nicoletti 1989, Boschiroli et al. 2001, Walker 2003).

Brucella abortus é o agente etiológico da brucelose bovina causador de uma das doenças infecciosas que causam enormes perdas econômicas à cadeia da bovinocultura de corte e de leite, devido aos prejuízos causados em consequência dos distúrbios reprodutivos ocasionados nos animais (Poester et al. 2002, Monreal et al. 2003). Esta zoonose é responsável por problemas sanitários e econômicos, particularmente nos trópicos e em países com pouco investimento nas áreas de produção de leite e carne, onde a sua incidência é alta (Poester et al. 2002).

Desde a identificação do agente etiológico da brucelose, vários pesquisadores têm procurado desenvolver vacinas que sejam protetoras e não induzam a produção de anticorpos que interfiram no diagnóstico da doença (Brasil 2006). Em decorrência desses estudos, vem sendo desenvolvido um grande número de vacinas vivas atenuadas, mortas, de subunidades, recombinantes e de DNA, com o intuito de produzir um imunógeno que além de prevenir a infecção bacteriana em ambos os sexos, não provoque a doença nos animais vacinados, previna o aborto, promova um longo período de proteção com uma única dose, não interfira nos testes de diagnóstico, seja biologicamente estável e não apresente risco de reverter a virulência, não seja prejudicial aos humanos, não deixe resíduos no leite, e principalmente, que quando produzida em alta escala tenha um baixo custo (Oliveira 2011).

As espécies de Brucella apresentam características peculiares de resistência ao hospedeiro, induzindo infecções crônicas e persistentes, sobrevivendo e se multiplicando dentro de células fagocíticas (Oliveira et al. 2002, Sexton \& Vogel 2002). Essas habilidades são determinadas pelos fatores de virulência associados a essa bactéria. 0 sistema de secreção do tipo IV é um dos cinco principais sistemas que são capazes de exportar moléculas relacionadas à virulência através da membrana de bactérias gram-negativas. Brucella spp. possuem um sistema de secreção do tipo IV codificado por um operon virB, o qual é essencial para a sobrevivência e multiplicação dentro das células hospedeiras (O'Collaghan et al. 1999).

A região virB no genoma de B. abortus e Brucella suis é constituída por 12 janelas abertas de leitura (ORF, do inglês, Open Reading Frame) estruturadas em um operon, que é uma unidade genética de expressão coordenada (Boschiroli et al. 2002), sendo a proteína VirB5 um componente essencial para a maioria dos sistemas de secreção do tipo IV (Yeo et al. 2003).

Muitas vacinas testadas até o momento mostraram-se pouco protetoras, como as vacinas de amostras mortas, ou ainda estão em fase de testes, como as vacinas de subunidades, recombinantes e de DNA. As vacinas atenuadas são aquelas que são utilizadas nos programas de controle da brucelose, sendo duas delas recomendadas e empregadas atualmente pela Organização Mundial de Saúde Animal (OIE), a saber: a B19 e a vacina não indutora de anticorpos aglutinantes, a RB51. Ambas são boas indutoras de imunidade celular (Brasil 2006).

No Brasil, o Programa Nacional de Controle e Erradicação da Brucelose e da Tuberculose (PNCEBT) adotou no ano de 2001 a vacina B19 contra a brucelose para a imunização em massa de fêmeas entre três e oito meses de idade. No ano de 2007 foi aprovada a Instrução Normativa (IN) DSA-MAPA no13 (28/08/2007) que regulamentou o uso da vacina RB51 restringindo sua administração para fêmeas que não foram vacinadas com a amostra B19 e para fêmeas adultas não reagentes aos testes sorológicos em estabelecimentos de criação com foco de brucelose (Brasil 2007).

Dentre as vacinas vivas, a amostra vacinal B19 é a mais utilizada nos programas de controle em vários países (Lage et al. 2009). Esta é uma amostra lisa, pois expressa a cadeia 0 em seu lipopolissacarídeo (LPS), induzindo uma resposta sorológica que pode produzir um resultado sorológico falso-positivo se aplicada fora da faixa etária preconizada ou em animais testados antes dos 24 meses de idade. Os testes sorológicos de referência não distinguem animais vacinados de animais infectados a campo (Cheville et al. 1993, Olsen \& Tatum 2010).

A identificação molecular da amostra vacinal B19 está baseada em um gene ligado ao catabolismo do eritritol (ery) e este tem sido descrito na literatura como um importante marcador na diferenciação de B19 das amostras de campo (Ewalt \& Bricker 2000). As espécies pertencentes ao gênero Brucella utilizam preferencialmente a via metabólica do eritritol (álcool polihídrico), promovendo o crescimento das amostras em meios ricos na presença deste álcool. A amostra vacinal atenuada B19 sofreu uma deleção natural de 702 pares de bases (pb) no gene ery, ocorrendo a inibição do crescimento dessa amostra na presença desse álcool (Sangari et al. 2000, Miyashiro et al. 2007). Entretanto, foi observado que amostras da vacina B19, comercializadas na Índia, não possuem essa deleção, porém apresentaram redução da virulência em camundongos BALB/c (Mukherjee et al. 2005). Esse dado mostra a importância da genotipagem do gene ery em amostras comercializadas, inclusive naquelas utilizadas no Brasil.

A amostra vacinal rugosa RB51 não possui o antígeno-0 no LPS, desta forma as amostras rugosas não interferem no diagnóstico sorológico da brucelose por não possuírem este componente responsável pela indução de anticorpos. Esta amostra foi derivada da amostra lisa e virulenta S2308 de B. abortus, obtida por passagens em meios de cultura contendo doses sub-inibitórias de rifampicina e penicilina (Schurig et al. 1991, Poester et al. 2002, Samartino 2003).

A vacina RB51 de B. abortus é administrada em vários países e vem sendo utilizada como alternativa para a amostra vacinal B19 na prevenção da brucelose. Os animais vacinados com RB51 mostraram maior resistência à infecção e uma diminuição da incidência de aborto (Schurig et al. 1991, Cheville et al. 1996). Entretanto, um relato de caso realizado no Irã mostrou a ocorrência de aborto após a va- 
cinação com RB51 e a presença desta amostra no feto abortado (Yazdi et al. 2009).

A vacina RB51 quando utilizada em dose única produz um efeito protetor em bovinos similar à vacina B19, com a vantagem de ser menos patogênica para os seres humanos e de ser diferenciada de isolados de campo. Porém, esta amostra tem a desvantagem de ser resistente à rifampicina, um dos antibióticos usados no tratamento contra a brucelose humana (WHO 1997).

A amostra vacinal RB51 apresenta no gene wboA, envolvido na síntese da cadeia 0 , um elemento de inserção denominado IS711, que é um fragmento de 842 pb delimitado por repetições in tanden de $20 \mathrm{pb}$, que interrompe a síntese da cadeia 0 quando inserido no gene $w b o \mathrm{~A}$ (Vemulapalli et al. 1999). Este elemento está presente em cinco ou mais cópias no genoma de Brucella spp., mostrando ser completamente estável em número e posição no cromossomo (Halling \& Zehr 1990, Bricker \& Halling 1994, Bricker \& Halling 1995). Entretanto, diferenças no número de elementos foram relatadas, como o biovar 1 de Brucella abortus que possui sete cópias (Ouahrani et al. 1993, Bricker \& Halling 1995, Ocampo-Sosa \& García-Lobo 2008). Estes elementos, por serem segmentos discretos de DNA ligados ao polimorfismo da bactéria, são usados na diferenciação entre amostras de RB51 das demais variações de biovares e espécies de Brucella (Ouahrani et al. 1993, Bricker \& Halling 1994).

De acordo com o pressuposto, o objetivo neste estudo foi analisar amostras vacinais B19 e RB51 comercializadas no Brasil, a fim de verificar possíveis mutações genéticas em relação às amostras referências.

\section{MATERIAL E MÉTODOS}

Obtenção de amostras vacinais e não vacinais. Foi realizada uma pesquisa junto ao Ministério da Agricultura Pecuária e Abastecimento (MAPA) para a obtenção de todas as amostras vacinais B19 e RB51 liberadas para comercialização no Brasil. As amostras de referência USDA B19 (Departamento de Agricultura dos Estados Unidos - USDA), e USDA RB51 foram gentilmente cedidas pelo LANAGRO-MG (MAPA) e a amostra virulenta S2308 foi adquirida de coleção biológica certificada.

As amostras vacinais foram adquiridas em estabelecimentos comerciais autorizados para venda destes produtos e junto ao MAPA. Estas vacinas foram produzidas por empresas brasileiras no período de 2007 a 2009. Um frasco de cada vacina RB51 foi adquirido e denominado A e B, e quatro amostras vacinais de B19 foram adquiridas e denominadas $\mathrm{C}, \mathrm{D}, \mathrm{E}$ e F. As amostras vacinais B19 denominadas G, H, I, J, L e M foram gentilmente cedidas pelo LANAGRO-MG. Todas as vacinas comerciais utilizadas neste estu- do foram aprovadas no controle biológico, conforme determinado pelo MAPA. As amostras vacinais foram reidratadas em água destilada estéril, de acordo com as instruções dos fabricantes.

Uma vez reconstituídas, todas as amostras foram cultivadas em meio Trypic Soy Agar (TSA) e colônias isoladas foram cultivadas em meio Trypic Soy Broth (TSB), estocadas em glicerol 20\% e armazenadas a $-70^{\circ} \mathrm{C}$ para utilização em ensaios subsequentes.

Meios e condições de cultivo. Para cada ensaio as amostras vacinais e as amostras de referência foram descongeladas e cultivadas em meio TSA por 72 horas a $37^{\circ} \mathrm{C}$. Posteriormente uma colônia isolada de cada amostra foi crescida em $10 \mathrm{~mL}$ de meio TSB a $37^{\circ} \mathrm{C}$ sob agitação constante por 72 horas.

Extração do DNA genômico das amostras. Para a extração do DNA genômico, as culturas em meio TSB foram centrifugadas por 30 minutos a $3000 \mathrm{xg}$. 0 sobrenadante foi descartado e posteriormente foi adicionado ao sedimento $30 \mathrm{~mL}$ de PBS $1 \mathrm{X}, \mathrm{pH} 7,2$, centrifugou-se novamente e em seguida foram adicionados ao sedimento 8mL de SDS (Dodecil Sufato de Sódio) 20\% e a amostra foi homogeneizada por vórtex e incubada a $65^{\circ} \mathrm{C}$ por 1 hora. Foram adicionados $16 \mathrm{~mL}$ de clorofórmio seguido de agitação vigorosa, adicionados $4 \mathrm{~mL}$ da solução de precipitação protéica (3M $\mathrm{C}_{2} \mathrm{H}_{3} \mathrm{KO}_{2}, 2 \mathrm{M} \mathrm{CH}_{3} \mathrm{COOH}$ ) e homogeneizado novamente. A amostra foi centrifugada a $3000 \mathrm{xg} / 30 \mathrm{~min}$. O sobrenadante foi coletado e tratado com $30 \mathrm{~mL}$ de etanol P.A. gelado e homogeneizado por inversão até formar um precipitado e em seguida o material foi armazenado à $-20^{\circ} \mathrm{C}$ por 16 horas. $\mathrm{Na}$ etapa seguinte o material foi centrifugado à $3000 \mathrm{xg} / 15 \mathrm{~min}$. 0 sobrenadante foi descartado e ao sedimento formado foram adicionados $15 \mathrm{~mL}$ de etanol $80 \%$. Logo após, a amostra foi centrifugada a $3000 \mathrm{x} \mathrm{g/5} \mathrm{min} \mathrm{e}$ o sobrenadante descartado. 0 sedimento foi seco a temperatura ambiente e ressuspensso em $600 \mu \mathrm{L}$ de água ultra pura e incubado a $65^{\circ} \mathrm{C}$ por 5 minutos. Adicionou-se $8 \mu \mathrm{L}$ de solução de RNAse $(20 \mathrm{ng} / \mu \mathrm{L})$ e incubou-se à $37^{\circ} \mathrm{C}$ por 30 minutos. Posteriormente o DNA foi estocado a $-20^{\circ} \mathrm{C}$. A concentração e o grau de pureza dos DNAs extraídos foram avaliados em espectrofotômetro (Gene Quant $\AA$, Amersham Pharmacia, EUA), sob absorbância de $260 \eta m$ e $280 \eta \mathrm{m}$. Em seguida todas as amostras de DNA foram concentradas a $100 \mathrm{ng} / \mu \mathrm{L}$ e a qualidade das amostras foi observada em gel de agarose 1\%, corado com Sybr Gold @ (Invitrogen) e visualizadas em transiluminador ultravioleta.

Escolha dos genes. A escolha dos genes foi baseada em dados da literatura balizada em estudos para a identificação e caracterização de espécies e biovares de Brucella. 0 par de oligonucleotídeos VIRB5 foi desenhado para confirmação do gênero Brucella. A inserção do elemento IS711 foi utilizada para genotipagem das amostras vacinais RB51 (Vemulapalli et al. 1999) e o gene ery, essencial para o catabolismo do eritritol, foi utilizado para a avaliação dos genótipos das amostras vacinais B19 (Miyashiro et al. 2007). Os oligonucleotídeos utilizados neste estudo estão listados no Quadro 1.

Amplificação dos genes pela PCR. As reações de PCR foram realizadas em um volume total de $20 \mu \mathrm{l}$, com cada reação contendo 100ทg de DNA, 0,03mM $\mathrm{MgCl}_{2}, 0,25 \mathrm{pMol}$ oligonucleotídeos, $0,3 \mathrm{mM}$ dNTP`s e 1,5 U de taq DNA polimerase.

Quadro 1. Sequência dos oligonucleotídeos utilizados para identificação e verificação de possíveis mutações nas vacinas comercializadas

\begin{tabular}{crc}
\hline Oligonucleotídeos & Sequência & Autor \\
\hline VIRB5F & 5`TCTACGAAGCGGTGATGAGCG3` & Este estudo \\
VIRB5R & 5'GGTGTAGATGATGTGTTGCGTG3` & Este estudo \\
ERY1 & 5'TTGGCGGCAAGTCCGTCGGT3' & Miyashiro et al. (2004) \\
ERY2 & 5'CCCAGAAGCGAGACGAAACG3' & Miyashiro et al. (2004) \\
IS711AF & 5`TTAAGCGCTGATGCCATTTCCTTCAC3` & Vemulapalli et al. (1999) \\
IS711BF & 5`TTTAGTTTGCCGTAATATAGGTCTAGAACCTGTC3` & Vemulapalli et al. (1999) \\
IS711CR & 5`GCCAACCAACCCAAATGCTCACAA3` & Vemulapalli et al. 1999)
\end{tabular}


A reação foi realizada utilizando-se os DNAs extraídos das amostras vacinais B19 e RB51, das amostras de referência USDA B19 e USDA RB51, e da amostra virulenta S2308 com o par de oligonucleotídeos VIRB5F e VIRB5R específicos do gênero Brucella. Para a diferenciação da amostra vacinal B19 a reação foi realizada utilizando os oligonucleotídeos ERY1 e ERY2, relacionados com a deleção dos 702 pb referentes ao gene ery (Sangari \& Aguero 2000). 0 ciclo de temperaturas empregado foi de desnaturação a $94^{\circ} \mathrm{C}$ por 10 minutos e, ao final, extensão de $72^{\circ} \mathrm{C}$ por 10 minutos. Na primeira reação foram empregados 35 ciclos divididos em três fases: desnaturação a $94^{\circ} \mathrm{C}$ por 1 minuto, anelamento a $68^{\circ} \mathrm{C}$ por 2 minutos e extensão a $72^{\circ} \mathrm{C}$ por 2 minutos.

Também foram utilizados os oligonucleotídeos IS711AF, IS711BF e IS711CR relacionados com a inserção do elemento IS711 no gene wboA (Vemulapalli et al. 1999).

0 ciclo de temperaturas empregado procedeu-se de desnaturação $95^{\circ} \mathrm{C}$ por 1 minuto e, ao final, extensão de $72^{\circ} \mathrm{C}$ por 10 minutos. Na reação foram empregados 40 ciclos divididos em três fases: desnaturação a $95^{\circ} \mathrm{C}$ por 1 minuto, anelamento a $60,5^{\circ} \mathrm{C}$ por 1 minuto e extensão a $72^{\circ} \mathrm{C}$ por 1 minuto e 30 segundos. Duas diferentes amplificações de PCR foram realizadas com combinações de oligonucleotídeos IS711AF e IS711CR e oligonucleotídeos IS711BF e IS711CR.

A análise do produto amplificado foi realizada por eletroforese em gel de agarose 1\%, corado com Sybr Gold (Invitrogen) e visualizado em transiluminador ultravioleta.

\section{RESULTADOS}

Todas as amostras vacinais testadas utilizando os oligonucleotídeos VIRBB5 amplificaram um fragmento esperado de 513 pb (Fig.1), confirmando que todas as amostras são do gênero Brucella.

A característica da deleção de 702 pb referente ao gene ery foi encontrada em todas as amostras vacinais B19 e na amostra de referência USDA B19, onde foi possível observar fragmentos de $361 \mathrm{pb}$ amplificados pelos oligonucleotídeos ERY1 e ERY2, diferente da amostra virulenta S2308 que apresentou um fragmento de $1063 \mathrm{pb}$, que corresponde ao gene ery intacto. Os resultados da deleção do gene ery utilizados para a análise das amostras vacinais B19 são mostrados na Figura 2 e resumidos no Quadro 2.

Na reação de PCR realizada com os oligonucleotídeos IS711AF e IS711CR foi possível verificar a inserção do ele-

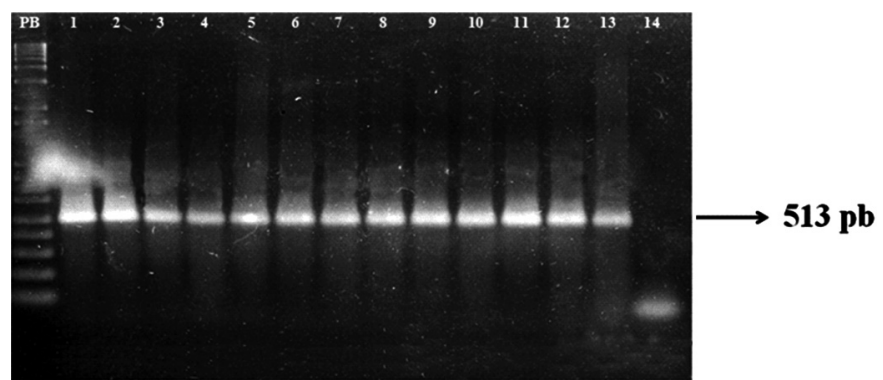

Fig.1. Perfil eletroforético em gel de agarose 1\% da PCR do gene virB5. Resultado da PCR usando os oligonucleotídeos VIRB5F e VIRB5R; (PB) Padrão de pares de base $1 \mathrm{~Kb}$ Plus DNA Ladder, Invitrogen $\AA$; (1-2) Amostra vacinal RB51 (A e B); (3-12) Amostra vacinal B19 (C a M); (13) Amostra virulenta S2308; (14) Controle negativo.

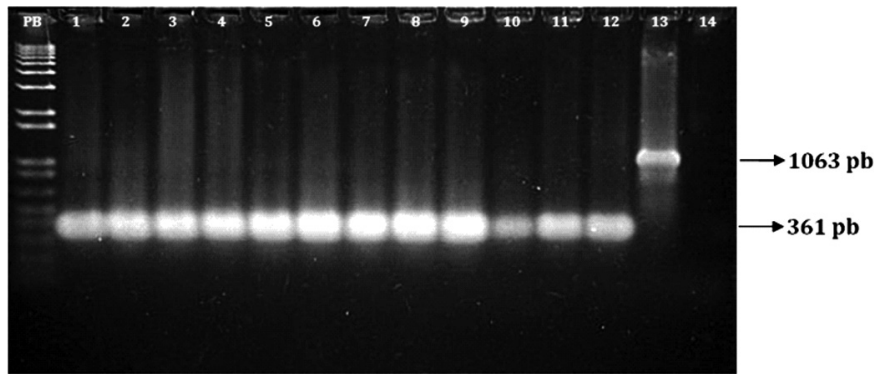

Fig.2. Perfil eletroforético em gel de agarose 1\% da PCR do gene ery. Resultado da PCR usando os oligonucleotídeos ERY1 e ERY2; (PB) Padrão de pares de base $1 \mathrm{~Kb}$ Plus DNA Ladder, Invitrogen $\AA$; (1-10) Amostra vacinal B19 (C a M); (11-12) Amostra de referência USDA B19; (13) Amostra virulenta S2308; (14) Controle negativo.

mento IS711 no gene wboA, observado um fragmento de $1300 \mathrm{pb}$ nas amostras vacinais RB51 e na amostra de referência USDA RB51, diferenciando-as da amostra virulenta S2308 que apresentou um fragmento de $400 \mathrm{pb}$, referente somente a uma região do gene wboA (Fig.3).

Quando os oligonucleotídeos IS711BF e IS711CR foram utilizados para amplificação do elemento IS711, as amostras vacinais RB51, as amostras de referência USDA RB51 e a amostra virulenta S2308 apresentaram um fragmento de aproximadamente $900 \mathrm{pb}$ (Fig. 4) referente ao elemento de

Quadro 2. Resultados das amplificações pela reação de PCR para diferenciação das amostras virulenta S2308, vacinais B19 e RB51 e de referência USDA B19 e USDA RB51

\begin{tabular}{|c|c|c|c|c|c|}
\hline \multirow[t]{2}{*}{ Amostra } & \multirow[t]{2}{*}{ Origem } & \multicolumn{4}{|c|}{ Oligonucleotídeos } \\
\hline & & virB5F/virB5R & Ery1/Ery2 & IS711AF/IS711R & IS711BF/IS711CR \\
\hline Amostra A & Vacinal RB51 & $513 \mathrm{pb}$ & & $1300 \mathrm{pb}$ & $900 \mathrm{pb}$ \\
\hline Amostra B & Vacinal RB51 & $513 \mathrm{pb}$ & & $1300 \mathrm{pb}$ & $900 \mathrm{pb}$ \\
\hline Amostra C & Vacinal B19 & $513 \mathrm{pb}$ & $361 \mathrm{pb}$ & & \\
\hline Amostra D & Vacinal B19 & $513 \mathrm{pb}$ & $361 \mathrm{pb}$ & & \\
\hline Amostra E & Vacinal B19 & $513 \mathrm{pb}$ & $361 \mathrm{pb}$ & & \\
\hline Amostra F & Vacinal B19 & $513 \mathrm{pb}$ & $361 \mathrm{pb}$ & & \\
\hline Amostra G & Vacinal B19 & $513 \mathrm{pb}$ & $361 \mathrm{pb}$ & & \\
\hline Amostra H & Vacinal B19 & $513 \mathrm{pb}$ & $361 \mathrm{pb}$ & & \\
\hline Amostra I & Vacinal B19 & $513 \mathrm{pb}$ & $361 \mathrm{pb}$ & & \\
\hline Amostra J & Vacinal B19 & $513 \mathrm{pb}$ & $361 \mathrm{pb}$ & & \\
\hline Amostra L & Vacinal B19 & $513 \mathrm{pb}$ & $361 \mathrm{pb}$ & & \\
\hline Amostra M & Vacinal B19 & $513 \mathrm{pb}$ & $361 \mathrm{pb}$ & & \\
\hline USDA B19 & Referência B19 & $513 \mathrm{pb}$ & $361 \mathrm{pb}$ & & \\
\hline USDA RB51 & Referência RB51 & $513 \mathrm{pb}$ & & $1300 \mathrm{pb}$ & $900 \mathrm{pb}$ \\
\hline S2308 & Virulenta S2308 & $513 \mathrm{pb}$ & $1063 \mathrm{pb}$ & $400 \mathrm{pb}$ & $900 \mathrm{pb}$ \\
\hline
\end{tabular}




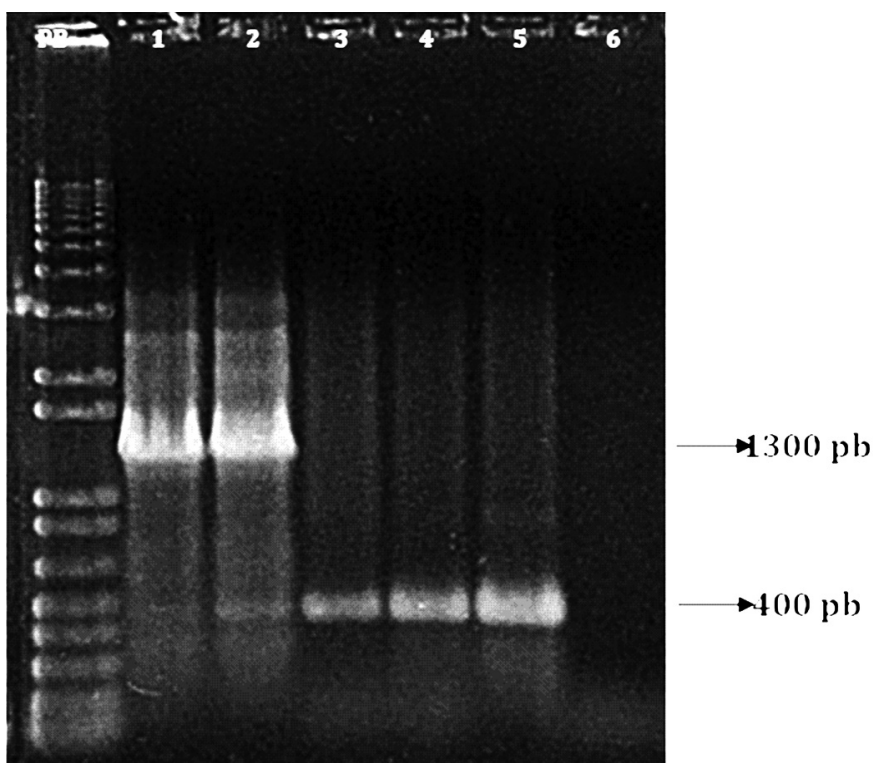

Fig.3. Perfil eletroforético em gel de agarose 1\% da PCR do gene IS711. Resultado da PCR usando os oligonucleotídeos IS711AF e IS711CR; (PB) Padrão de pares de base $1 \mathrm{~Kb}$ Plus DNA Ladder, Invitrogen $®$; (1-2) Amostra vacinal RB51(A e B); (3-4) Amostra de referência USDA RB51; (5) Amostra virulenta S2308; (6) Controle negativo.

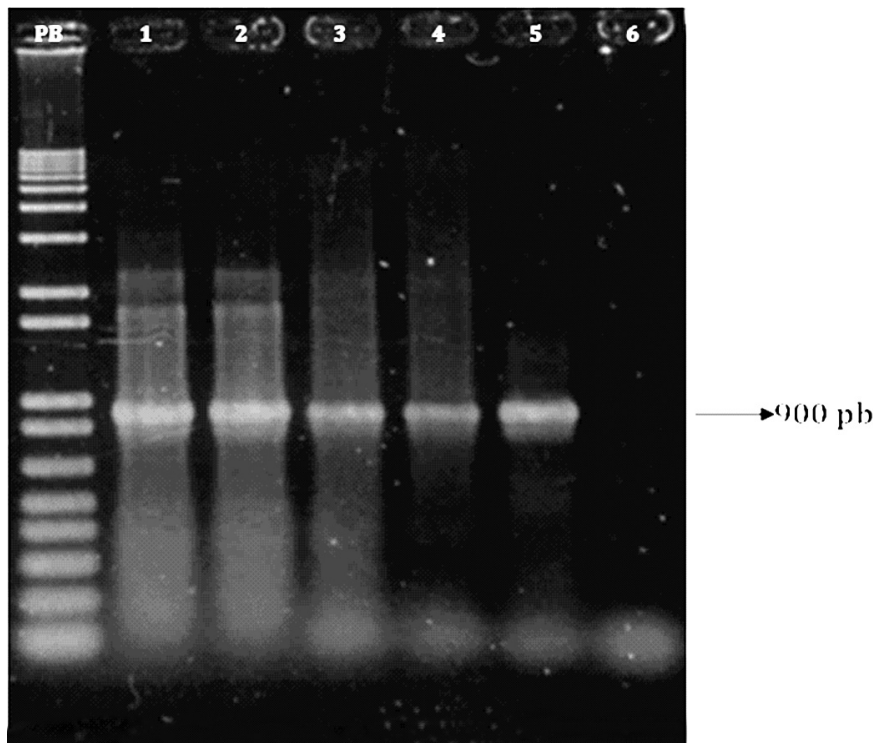

Fig.4. Perfil eletroforético em gel de agarose 1\% da PCR do gene IS711. Resultado da PCR usando os oligonucleotídeos IS711BF e IS711CR; (PB) Padrão de pares de base $1 \mathrm{~Kb}$ Plus DNA Ladder, Invitrogen $®$; (1-2) Amostra vacinal RB51(A e B); (3-4) Amostra de referência USDA RB51; (5) Amostra virulenta S2308; (6) Controle negativo.

inserção IS711, pois a presença de um fragmento amplificado na amostra virulenta S2308 esta relacionado à presença deste fragmento em outras regiões do genoma de Brucella.

\section{DISCUSSÃO}

0 uso de lotes de boa qualidade das amostras vacinais B19 e RB51 é um pré-requisito fundamental para o sucesso das campanhas de vacinação contra a brucelose, pois algumas características in vitro, tais como alterações da fase colonial, têm demonstrado ser um elemento importante que afeta a atividade biológica das vacinas (Bosseray 1991). Assim, deve-se ter o maior cuidado com a qualidade das vacinas comercializadas. Segundo Milward (1995), uma vacina não é apenas uma linhagem cultivada e testada em animais desafiados, e sim um produto que quando colocado nas mãos do usuário final, tem que ser confiável e fornecer os resultados esperados.

No presente estudo todas as amostras vacinais e controles amplificaram uma região conservada do gene virB 5 , que está inserido no operon virB, presente em todas as espécies de Brucella. 0 operon virB é formado por 12 genes (virB1 - virB12) que codificam proteínas internas e externas de membrana, sendo este um dos principais determinantes de virulência e sobrevivência das bactérias em meio intracelular (Sieira et al. 2000, Rouot et al. 2003).

A sensibilidade ao eritritol é considerada uma característica importante da amostra B19 de B. abortus, devido à deleção de 702 pb no gene ery. Todas as amostras B19 comercializadas no Brasil e testadas neste estudo mostraram-se com o padrão de deleção no gene ery, corroborando com os resultados descritos por Miyashiro et al. (2007), que observaram o mesmo perfil de fragmento quando diferenciaram as amostras de campo das amostras vacinais B19. Porém, estudos feitos na Índia constataram que as amostras vacinais HR 19 e IVRI, obtidas de coleções de culturas do tipo americanas (ATCC \#27565), utilizadas para a fabricação das amostras comercializadas neste país, não apresentaram a deleção do gene ery. E que algumas amostras que possuem a deleção de 702 pb no gene ery, e apresentaram crescimento na presença de eritritol, ainda que baixo (Mukherjee et al. 2005).

0 fenótipo rugoso da amostra vacinal RB51 está relacionado com a inserção do elemento IS711 no gene wboA, tornando-a menos patogênica (Vemulapalli et al. 1999). As duas amostras vacinais RB51 liberadas para comercialização no Brasil e testadas, apresentaram a característica de inserção do elemento IS711 no gene wboA. Apesar da amostra RB51 ser menos patogênica, estudos realizados no Irã relataram casos de aborto em fêmeas vacinadas com esta amostra (Yazdi et al. 2009).

A avaliação da estabilidade genética é um dos elementos essenciais para garantir a qualidade biológica de vacinas vivas contra a brucelose bovina. A genotipagem utilizando a combinação de 15 marcadores genéticos para análise de múltiplos lócus em tandem (MLVA), mostrou-se eficiente na identificação da variabilidade genética da amostra vacinal Rev1 de Brucella melitensis (Garcia-Youldi et al. 2007) e da amostra vacinal B19 de B. abortus (Miranda 2009).

Os resultados do presente estudo demonstraram que as amostras vacinais B19 e RB51 comercializadas no Brasil apresentam as características das amostras padrão USDA B19 e USDA RB51, ou seja, a deleção de 702 pb no gene ery $e$ a inserção do fragmento IS711 no gene wboA, respectivamente. Desta forma, o presente estudo corrobora com a qualidade genética, quanto à estabilidade dos genes analisados, das amostras vacinais de Brucella abortus B19 e RB51 disponíveis e utilizadas em bovinos pelo PNCEBT. 
Agradecimentos.- Ao Conselho Nacional de Desenvolvimento Científico e Tecnológico (CNPq) pelo apoio financeiro, por meio do Edital $\mathrm{CNPq}$ / MAPA/SDA №64/2008, e à Empresa Brasileira de Pesquisa Agropecuária (Embrapa), por meio do Macroprograma 3 (Proc.03.08.01.004.00.00).

\section{REFERÊNCIAS}

Boschiroli M.L., Foulongne V. \& O'Callaghan D. 2001. Brucellosis: A world wide zoonosis. Curr. Opin. Microbiol. 4:58-64.

Boschiroli M.L., Ouahrani-Bettache S., Foulongne V., Michux-Charachon S., Bourg G., llardet-Servent A., Cazevieille C., Liautard J.P., Ramuz M. \& O'Collaghah. 2002. The Brucella suis virB operon is induced intracellulary in macrophages. Proc. Natl Acad. Sci. 99:1544-1549

Bosseray N. 1991. Brucella melitensis Rev1 attenuated vaccine: Stability of markers, residual virulence and immunogenicity in mice. Biologicals 19:355-363.

Brasil 2006. Manual Técnico do Programa Nacional de Controle e Erradicação da Brucelose e Tuberculose (PNCEBT). Ministério da Agricultura, Pecuária e Abastecimento, Brasília. [Cited 2008 dez 18]. Available from <http://www.agricultura.gov.br/arq_editor/file/Aniamal/programa\%20nacional $\% 20$ sanidade $\% 20$ brucelose/Manual\%20do\%20PNCEBT\%20-\%200riginal.pdf>

Brasil 2007. Estabelece as condições para a vacinação de fêmeas bovinas contra brucelose, utilizando vacina viva não indutora de formação de anticorpos aglutinantes, amostra RB51 (PNCEBT). Instrução Normativa №33 de 24 de Agosto de 2007, Ministério da Agricultura, Pecuária e Abastecimento, Brasília, DF. Diário Oficial da União, Brasília, DF. 1:6.

Bricker B.J. \& Halling S.M. 1994. Differentiation of Brucella abortus bv.1, 2 and 4, Brucella melitensis, Brucella ovis and Brucella suis bv. 1 by PCR. J. Clin. Microbiol. 32:2660-2666.

Bricker B.J. \& Halling S.M. 1995. Enhancement of the Brucella AMOS PCR assay for differentiation of Brucella abortus vaccine strains S19 and RB51. J. Clin. Microbiol. 33:1640-1642.

Cheville N.F., Olsen S.C., Jensen A.E., Stevens M.G. \& Palmer M.V. 1996. Effects of age at vaccination on efficacy of Brucella abortus strain RB51 to protect cattle against brucellosis. Am. J. Vet. Res. 57:1153-1156.

Cheville N.F., Stevens M.G., Jensen A.E., Tatum F.M. \& Halling S.M. 1993. Immune responses and protection against infection and abortion in cattle experimentally vaccinated with mutants strains of Brucella abortus. Am. J. Vet. Res. 54:1591-1597.

Ewalt D.R. \& Bricker B.J. 2000. Validation of the abbreviated Brucella AMOS PCR as a rapid screening method for differentiation of Brucella abortus field strain isolates and the vaccine strains, 19 and RB51. J. Clin. Microbiol. 38:3085-3086.

García-Youldi D., LeFleche P., Marín C.M., De Miguel M.J., Muñoz P.M., Vergnaud G. \& López-Goñi I. 2007. Assessment of genetic stability of Brucella melitensis Rev1 vaccine strain by multiple-locus variable number tandem repeat analysis. Vaccine 25:2858-2862.

Halling S.M. \& Zehr E.S. 1990. Polymorphism in Brucella spp. due to highly repeated DNA. J. Bacteriol. 172:6637-6640.

Lage A.P., Poester F.P., Paixão T.A., Silva T.M.A., Xavier M.N., Minharro S., Miranda K.L., Alves C.M., Mol J.P.S. \& Santos R.L. 2008. Brucelose bovina: uma atualização. Revta Bras. Reprod. Anim. 32:202-212.

Milward F.W. 1995. Production and quality control of vaccines for brucellosis and a specific emphasis on Rev.1 vaccine. FAO/WHO/OIE Round table on the use of Rev.1 vaccine in small ruminants and cattle. CNEVA, Alfort, France.

Miranda K.L. 2009. Evaluation of brucellosis vaccines in Brazil. PhD Thesis, Universidade Federal de Minas Gerais, Belo Horizonte. 77p. Available from <http://www.bibliotecadigital.ufmg.br/dspace/bitstream/1843/ BUOS-8FXLKT/1/c_pia_de_tese_de_doutorado_de_karina_leite_miranda.pdf>

Miyashiro S., Scarcelli E., Piatti R.M., Campos F.R., Vialta A., Keid L.B., Dias R.A. \& Genovez M.E. 2007. Detection of Brucella abortus DNA in illegal cheese from São Paulo and Minas Gerais and differentiation of B19 vaccinal strain by means of the Polymerase Chain Reaction (PCR). Braz. J. Microbiol. 38:17-22.

Monreal D., Grilló M.J., González D., Marín C.M., De Miguel M.J., López-Goñi I., Blasco J.M., Cloeckaert A. \& Moriyón I. 2003. Characterization of Bru- cella abortus 0: Polysaccharide and core lipopolysaccharide mutants and demonstration that a complete core is required for rough vaccines to be efficient against Brucella abortus and Brucella ovis in the mouse model. Infect. Immun. 71:3261-3271.

Mukherjee F., Jain J., Grilló M.J., Blasco J.M. \& Nair M. 2005. Evaluation of Brucella abortus S19 vaccine strains by bacteriological tests, molecular analysis of ery loci and virulence in BALB/c mice. Biologicals 33:153160.

Nicoletti P.L. 1989. Relationship between animal and human disease. In: Young E.J. \& Corbel M.J. (Eds). Brucellosis: Clinical and laboratory aspects. CRC Press Inc., Boca Raton, Florida, p.41-51.

O'Callaghan D., Cazevieille C., Allardet-Servent A., Boschiroli M.L., Bourg G., Foulongne V., Frutos P., Kulakov Y. \& Ramuz M. 1999. A homologue of the Agrobacterium tumefaciens VirB and Bordetella pertussis Ptl type IV secretion systems is essential for intracellular survival of Brucella suis. Mol. Microbiol. 33:1210-1220.

Ocampo-Sosa A.A. \& García-Lobo J.M. 2008. Demonstration of IS711 transposition in Brucella ovis and Brucella pinnipedialis. BMC Microbiol. 8(17) doi:10.1186/1471-2180-8-17.

Oliveira S.C., Soeurt N. \& Splitter G. 2002. Molecular and cellular interactions between Brucella abortus antigens and host immune responses. Vet. Microbiol. 90:417-424.

Oliveira S.C., Giambartolomei G.H., Cassataro J. 2011. Confronting the barriers to develop novel vaccines against brucellosis. Expert Rev. Vaccines. 19:1291-1305.

Olsen S. \& Tatum F. 2010. Bovine Brucellosis. Vet. Clin. Food Anim. 26:1527.

Ouahrani S., Michaux S., Sri Widada J., Bourg G., Tournebize R., Ramuz R. \& Liautard J.P. 1993. Identification and sequence analysis of IS6501, an insertion sequence in Brucella spp.: Relationship between genomic structure and the number of IS6501 copies. J. Gen. Microbiol. 139:3265-3273.

Poester F.P., Gonçalves V.S. \& Lage A.P. 2002. Brucellosis in Brazil. Vet. Microbiol. 90:55-62.

Rouot B., Alvarez-Martinez M.T., Marius C., Menanteau P., Guilloteau L., Boigegrain R.A., Zumbihl R., O'Callaghan D., Domke N. \& Baron C. 2003. Production of the type IV secretion system differs among Brucella species as revealed with VirB5- and VirB8-specific antisera. Infect. Immun. 71:1075-1082.

Samartino L.E. 2003. Brucellosis in Argentina. Vet. Microbiol. 90:71-80.

Sangari FJ., Agüero J. \& Garcia-Lobo J.M. 2000. The genes for erythritol catabolism are organized as an inducible operon in Brucella abortus. Microbiology 146:487-495.

Schurig G.G., Roop R.M., Bagchi T., Boyle S., Buhrman D. \& Sriranganathan N. 1991. Biological properties of RB51; a stable rough strain of Brucella abortus. Vet. Microbiol. 28:171-188.

Sexton J. \& Vogel J.P. 2002. Type IVB-secretion by intracellular pathogens. Traffic 3:178-185.

Sieira R., Comerci D.J., Sánchez D.0. \& Ugalde R.A. 2000. A homologue of a operon required for DNA transfer in Agrobacterium is required in $\mathrm{Bru}$ cella abortus for virulence and intracellular multiplication. J. Bacteriol. 182:4849-4855.

Vemulapalli R., McQuiston J.R., Schurig G.G., Sriranganathan N., Halling S.M. \& Boyle S.M. 1999. Identification of an IS711 Element interrupting the wboA gene of Brucella abortus vaccine strain RB51 and a PCR assay to distinguish strain RB51 from other Brucella species and strains. Clin. Diagn. Lab. Immunol. 6:760-764.

Walker R.L. 2003. Brucella, p.185-191. In: Hirsh D.C. \& Zee Y.C. (Eds), Microbiologia Veterinária. Guanabara Koogan, Rio de Janeiro. 446p.

WHO 1997. The Development of New/Improved Brucellosis Vaccines: Report of a WHO Meeting, Geneva. Expert Committee on Brucellosis, World Health Organization Joint FAO/WHO.

Yazdi H.S., Kafi M., Haghkhah M., Tamadon A., Behroozikhah A.M. \& Ghane M. 2009. Abortions in pregnant dairy cows after vaccination with $B r u-$ cella abortus strain RB51. Vet. Rec. 165:570-571.

Yeo H.-J., Yuan Q., Beck M.R., Baron C. \& Waksman G. 2003. Structural and functional characterization of the VirB5 protein from the type IV secretion system encoded by the conjugative plasmid pKM101. PNAS 100:15947-15952. 